\title{
Clinical Significance of Platelet-Derived Growth Factor-C Expression in Colorectal Cancer*
}

\author{
Shinichi Yamauchi ${ }^{1}$, Satoru Iida ${ }^{1 \#}$, Megumi Ishiguro ${ }^{1}$, Toshiaki Ishikawa ${ }^{2}$, Hiroyuki Uetake ${ }^{2}$, \\ Kenichi Sugihara ${ }^{1}$ \\ ${ }^{1}$ Department of Surgical Oncology, Graduate School, Tokyo Medical and Dental University, Tokyo, Japan; ${ }^{2}$ Department of Transla- \\ tional Oncology, Graduate School, Tokyo Medical and Dental University, Tokyo, Japan.

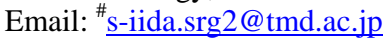

Received November $19^{\text {th }}, 2013$; revised December $11^{\text {th }}, 2013$; accepted December $18^{\text {th }}, 2013$

Copyright (C) 2014 Shinichi Yamauchi et al. This is an open access article distributed under the Creative Commons Attribution License, which permits unrestricted use, distribution, and reproduction in any medium, provided the original work is properly cited. In accordance of the Creative Commons Attribution License all Copyrights @ 2014 are reserved for SCIRP and the owner of the intellectual property Shinichi Yamauchi et al. All Copyright (C) 2014 are guarded by law and by SCIRP as a guardian.

\section{ABSTRACT}

Platelet-derived growth factors (PDGFs) are known to be associated with tumor growth and angiogenesis through their activation of the receptor tyrosine kinases, PDGF receptors alpha and beta. Several studies revealed the participation of the PDGF family in colorectal cancer (CRC). However, the role of platelet derived growth factor-C (PDGFC) in CRC is less well studied. This study aimed to determine the correlation between PDGFC expression and the prognosis of patients with CRCs. Tumor samples were obtained from patients with CRC who underwent surgical resection between 2002 and 2006. The mRNA expression of PDGFC was investigated by quantitative reverse transcription-polymerase chain reaction in 85 patients with stage I-IV CRC. PDGFC protein expression was analyzed by immunohistochemistry, and the relationship between PDGFC protein expression and clinicopathologic features was investigated in 245 patients with stage I-III CRC. PDGFC mRNA expression in cancer tissues was significantly higher in patients with distant metastases than in those without metastases $(P=\mathbf{0 . 0 1 6})$. PDGFC protein overexpression was associated with significantly worse overall and relapse-free survival $(P<0.0001$ and $P<0.0001$, respectively). Moreover, PDGFC protein overexpression was an independent risk factor for CRC recurrence (relative risk $=3.395,95 \%$ confidence interval $=1.895$ $6.081, P<0.001)$. In the present study, PDGFC overexpression appeared to be predictive of recurrence and poor prognosis in patients with CRC.

\section{KEYWORDS}

Platelet-Derived Growth Factor-C; Colorectal Cancer; Prognosis, mRNA Expression; Immunohistochemistry

\section{Introduction}

Colorectal cancer (CRC) is one of the most prevalent cancers in the world. It is the third most common cancer and the second most common cause of cancer-related mortality worldwide [1]. The mortality rate of this malignancy has changed little over the last 30 years despite advances in the understanding of the pathogenesis of this cancer at the molecular level. Approximately 20\% - 40\% of patients with CRC who undergo curative surgery develop local recurrence or distant metastases, resulting in

\footnotetext{
${ }^{*}$ No potential conflicts of interest were disclosed.

*Corresponding author.
}

shorter survival [2]. The tumor node metastasis (TNM) classification proposed by the International Union Against Cancer remains an important indicator of prognosis and provides the basis for therapeutic decisionmaking [3]. However, the current TNM classification system is limited in that it cannot predict prognosis for individual patients. To improve the prognosis of CRC, there is a crucial need to explore cancer-related genes that can serve as predictive biomarkers for individualization of therapy [4].

Concerning treatment, the introduction of targeted therapies, including the epidermal growth factor receptor (EGFR)-targeting monoclonal antibodies cetuximab and 
panitumumab and the vascular epithelial growth factor (VEGF)-targeting monoclonal antibody bevacizumab, has improved the median survival of patients with metastatic CRC to approximately 24 months. Several pathways for tumor growth and tumor angiogenesis, including VEGF, fibroblast growth factor (FGF), and platelet-derived growth factor (PDGF) pathways that have been identified recently, have attracted substantial interest due to their potential clinical application $[5,6]$.

The PDGF family is known to be associated with tumor growth and angiogenesis through activation of the receptor tyrosine kinases (RTKs) PDGF receptor (PDGFR) isoforms alpha and beta. A number of studies illustrated the importance of PDGFA and PDGFB in the recruitment of tumor stroma in skin cancer, melanoma, breast cancer, and lung cancer [7-10]. Conversely, PDGFC is a multi-domain protein with a C-terminal domain capable of binding to and activating PDGFR [11,12]. It is a potent mitogen for cells of mesenchymal origin, and its function as an inductor of liver fibrosis has been established [11-14]. A tumor growth-promoting function through the recruitment of fibroblasts has occasionally been described for PDGFC in a melanoma model and in hepatocellular carcinoma $[13,15,16]$. Although several reports revealed that the expression of PDGFs is related to CRC, the role of PDGFC in cancer, especially CRC, is less well studied. Few studies have revealed the relationship between PDGFC expression and clinical outcome using samples from patients with CRC. Thus, this study aimed to identify the correlation between PDGFC expression and the prognosis of patients with CRC.

\section{Methods}

\subsection{Patients}

Primary tumors from 262 consecutive patients who underwent surgical resection for CRC between 2002 and 2006 at Tokyo Medical and Dental University Hospital were included in our study. All patients provided written informed consent to participate in this study, and the Institutional Review Board approved the study (approval number: 831). Samples from 85 patients with stage I-IV CRC were submitted for quantitative reverse transcription-polymerase chain reaction (RT-PCR) analysis, including samples from 9 patients with stage I CRC, 25 patients with stage II CRC, 34 patients with stage III CRC, and 17 patients with stage IV CRC. The median follow-up time was 48 months for these patients (range: 1 - 66 months). Fourteen patients with stage I-III CRC experienced a relapse. We divided the 85 patients into two groups: the non-metastatic (stage I-III without recurrence, $n=54$ ) and metastatic (stage I-III with recurrence and stage IV, $\mathrm{n}=31$ ) groups. An immunohistochemical study was performed for 245 patients with stage I-III CRC, including 68 patients who underwent RT-PCR analysis, and for 17 patients with stage IV CRC who underwent RT-PCR analysis. Of 245 patients analyzed by immunohistochemistry, 55 had stage I disease, 92 had stage II disease, and 98 had stage III disease. The median follow-up time was 54 months for these patients (range: 1 - 97 months). Six patients with stage II CRC and 45 patients with stage III CRC received adjuvant chemotherapy with 5-fluorouracil/leucovorin (5FU/LV) or oral uracil and tegafur/leucovorin (UFT/LV) after radical resection. Among 17 patients with stage IV, 6 patients received systemic chemotherapy and 6 received hepatic arterial infusion (HAI) chemotherapy. Fifty-two patients with relapse received the following treatment; radical resection of metastatic lesions for 16 patients, systemic chemotherapy for 15 , systemic chemotherapy with HAI chemotherapy for 5, chemo-radiation therapy for 3 , and supportive therapy or others for 13 . The regimen of systemic chemotherapy included 5FU/LV, 5FU/ LV and oxaliplatin (FOLFOX), FOLFOX and bevacizumab, oral UFT/LV, oral UFT/LV and irinotecan (TEGAFIRI), irinotecan alone, S-1 alone, and S-1/irinotecan (IRIS).

\subsection{Quantitative RT-PCR}

Total RNA collected from bulk samples of cancer tissues and adjacent non-neoplastic tissues was extracted and purified using an RNeasy mini kit (QIAGEN) with oncolumn DNase digestion according to the manufacturer instructions. For cDNA synthesis, $10 \mu \mathrm{g}$ of total RNA was reverse-transcribed into cDNA using a High Capacity cDNA Reverse Transcription Kit (Applied Biosystems, Foster City, CA) according to the manufacturer protocol. TaqMan gene expression assays (Applied Biosystems: PDGFC, Hs00211916_m1; $\beta$-actin, Hs99999903_m1) were used to determine the expression of PDGFC. $\beta$-Actin was used as an internal control. PCR was performed using the TaqMan Universal PCR Master Mix (Applied Biosystems) with $1 \mu \mathrm{L}$ of cDNA in a 24$\mu \mathrm{L}$ final reaction volume. The thermal cycling conditions were as follows: $50^{\circ} \mathrm{C}$ for $2 \mathrm{~min}, 95^{\circ} \mathrm{C}$ for $10 \mathrm{~min}$, and 40 cycles of 15 -s denaturation at $95^{\circ} \mathrm{C}$ and 1-min annealing at $60^{\circ} \mathrm{C}$. All calculated concentrations of target genes were normalized to the amount of the endogenous reference by the comparative Ct method for relative quantification $\Delta \Delta \mathrm{Ct}$ method) using Relative Quantification Study Software (7300 Sequence Detection System version 1.2.1; Applied Biosystems). Each assay was performed in duplicate.

\subsection{Immunohistochemistry}

Immunohistochemical studies of PDGFC expression were conducted using formalin-fixed, paraffin-embedded 
surgical sections. Following deparaffinization in xylene and antigen retrieval by microwaving (Microwave-MI 77; Azumaya Corporation, Tokyo, Japan), pretreatment at $98^{\circ} \mathrm{C}$ was performed for $30 \mathrm{~min}$ in a high $\mathrm{pH}$ target retrieval solution (Dako, Carpentaria, CA). The endogenous peroxidase activity was quenched by 15-min incubation in a mixture of $3 \%$ hydrogen peroxide solution in $100 \%$ methanol. After washing with phosphate-buffered saline (PBS), nonspecific binding was blocked by treating slides with $10 \%$ normal rabbit serum IgG (Nichirei Bioscience, Tokyo, Japan) for 10 min. Following washing with PBS, the specimens were incubated with a goat polyclonal antibody against human PDGFC (sc-182280; Santa Cruz Biotechnology, CA) at a 1:50 dilution overnight at $4^{\circ} \mathrm{C}$ after 60 -min incubation at room temperature. Sections were washed with $0.1 \%$ Tween 20/PBS thrice and incubated with peroxidase-labeled anti-goat antibody (Histofine Simple Stain Max PO(G); Nichirei Bioscience) for $30 \mathrm{~min}$ at room temperature. Peroxidase activity was detected via incubation with $0.02 \%$ 3,3'-diaminobenzidine tetrahydrochloride (Nichirei Bioscience) for $30 \mathrm{~min}$. The sections were counterstained with hematoxylin. PDGFC expression was graded by two independent observers. The semiquantitative assessment of PDGFC immunostaining included both the intensity ( 0 , no staining; 1 , weak staining; 2 , moderate staining; and 3 , strong staining, as compared with positive internal controls) and extent of staining $(1,<10 \%$; $2,10 \%-40 \%$; $3,41 \%-70 \%$; and $4,>71 \%)$. The scores were determined by the sum of the intensity grade and the extent of staining grade (range of scores, 1 - 7).

\subsection{Statistical Analysis}

Statistical analyses of PDGFC expression were conducted using SPSS (version 17.0, SPSS Inc.) for Windows software. Differences between groups were estimated using the Mann-Whitney $U$ test, the Wilcoxon signed-rank test, and the $\chi^{2}$ test. Correlation was estimated using Spearman's rank correlation coefficient. Survival curves were estimated using the Kaplan-Meier method, and comparisons between curves were made using the log-rank test. Prognostic factors were estimated using univariate and multivariate analyses (Cox proportional hazards model). $P<0.05$ denoted statistical significance.

\section{Results}

\subsection{Expression of PDGFC mRNA in Cancer and Normal Tissues}

Quantitative RT-PCR analyses of 85 patients with stage I-IV CRC revealed that PDGFC mRNA expression levels were significantly higher in cancer tissues than in adjacent noncancerous tissues $(P<0.001$; Figure 1 (a)). The

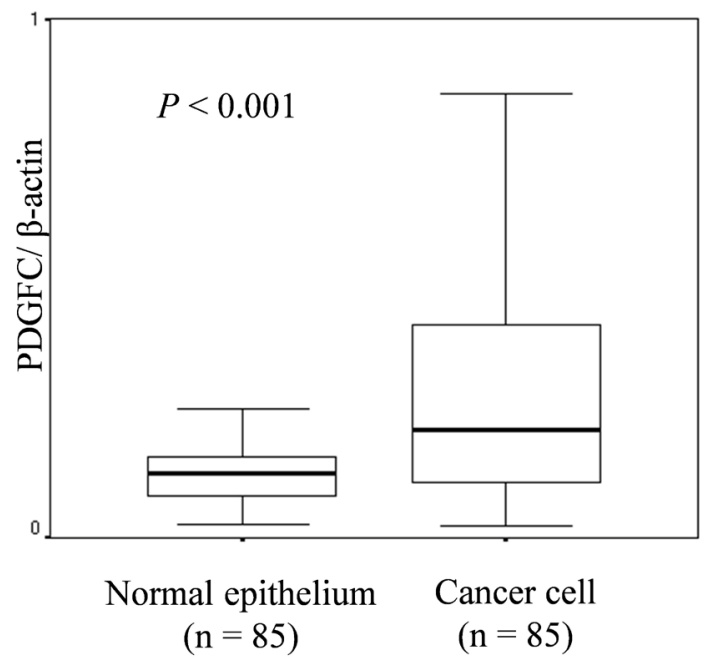

(a)

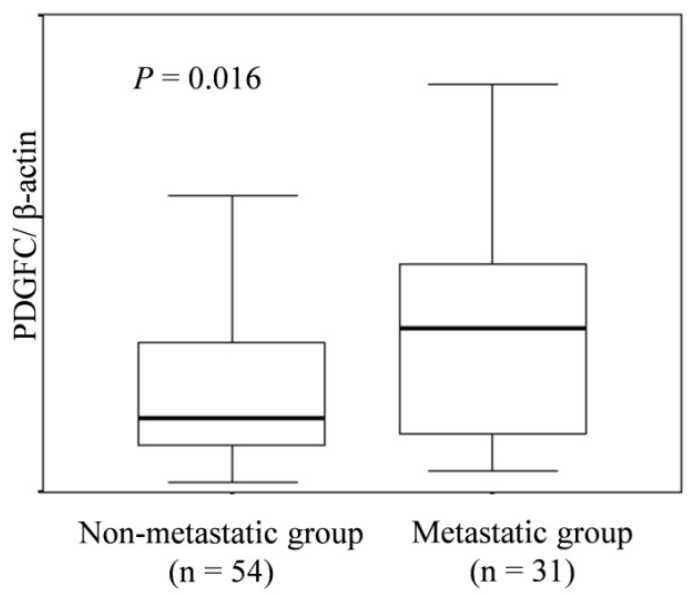

(b)

Figure 1. PDGFC mRNA expression by qRT-PCR analysis in 85 patients with stage I-IV CRC. (a) Cancer tissues showed higher PDGFC expression than normal epithelium in 85 patients $(\mathrm{P}<0.001)$. (b) PDGFC expression was higher in patients with distant metastases or recurrence (metastatic group: $n=31$ ) than in patients without distant metastases (non-metastatic group: $n=54 ; P=0.016$ ).

mRNA expression of PDGFC in cancer tissues was significantly higher in patients with distant metastases and recurrence $(\mathrm{n}=31)$ than those without metastases $(\mathrm{n}=54$, $P=0.016$; Figure 1(b)). Concerning other clinicopathologic parameters, depth of tumor invasion (T1-T3 versus T4), lymphatic invasion, lymph node metastasis, and carcinoembryonic antigen (CEA) level before surgical resection $(<5 \mathrm{ng} / \mathrm{ml}$ versus $\geq 5 \mathrm{ng} / \mathrm{ml})$ were significantly associated with metastatic CRC $(P=0.002, P=0.001, P$ $<0.001$, and $P<0.001$, respectively).

\subsection{PDGFC Protein Expression in Cancer and Normal Tissues}

The results obtained for PDGFC protein expression in 
CRC and normal colorectal epithelium are shown in Figure 2. PDGFC expression was detected in the membrane and cytoplasm of cancer cells. There was no significant localization of staining in cancer tissues. In normal epithelial cells, 162 patients (74.3\%) displayed no staining or only weak staining and 56 patients (25.6\%) exhibited moderate to strong staining. A significant correlation between the staining score in cancer cells and staining in normal epithelium was observed in our study $(P=0.041)$. PDGFC mRNA expression was correlated with protein expression in the 85 patients who underwent RT-PCR analysis (correlation coefficient $\mathrm{r}=0.247, P=$ 0.022; Figure 3).

\subsection{High PDGFC Protein Expression Correlates with Clinicopathologic Variables and Survival}

The experimental samples from patients without stage IV CRC that were used for immunohistochemical analysis were divided into two groups: the low expression (staining score $\leq 5, \mathrm{n}=144[58.7 \%])$ and high -expression groups (staining score $\geq 6, \mathrm{n}=101[41.2 \%]$ ). There were 26 patients (10.6\%) with no staining or almost no staining in cancer cells. Table 1 shows PDGFC protein expression in cancer samples and the clinicopathologic data of 245 patients with stage I, II, or III CRC. The high expression group had significantly greater frequencies of lymphatic invasion $(P=0.032)$, venous invasion $(P=$
Table 1. Correlation between clinicopathological features and PDGFC expression in stage I-III CRCs ${ }^{\mathrm{a}}$.

\begin{tabular}{|c|c|c|c|c|}
\hline \multicolumn{2}{|l|}{ Variables } & \multicolumn{2}{|c|}{ PDGFC expression } & \multirow{2}{*}{$P$} \\
\hline & & \multicolumn{2}{|c|}{ Low $(n=144)$ High $(n=101)$} & \\
\hline Age (median), $\mathrm{y}$ & & $31-92(66)$ & 20 - 85 (64) & 0.289 \\
\hline \multirow{2}{*}{ Gender } & Male & 86 & 75 & \multirow{2}{*}{0.022} \\
\hline & Female & 57 & 26 & \\
\hline \multirow{2}{*}{ Location } & Colon & 96 & 66 & \multirow{2}{*}{0.772} \\
\hline & Rectum & 47 & 35 & \\
\hline \multirow[b]{2}{*}{ Histology } & Well & 64 & 38 & \multirow[b]{2}{*}{0.267} \\
\hline & $\begin{array}{l}\text { Moderate, poor } \\
\text { and others }\end{array}$ & 79 & 63 & \\
\hline \multirow{2}{*}{ Depth } & $\mathrm{T} 1 / \mathrm{T} 2 / \mathrm{T} 3$ & 104 & 65 & \multirow{2}{*}{0.164} \\
\hline & $\mathrm{T} 4$ & 39 & 36 & \\
\hline \multirow{2}{*}{$\begin{array}{l}\text { Lymphatic } \\
\text { invasion }\end{array}$} & Absent & 49 & 22 & \multirow{2}{*}{0.032} \\
\hline & Present & 93 & 79 & \\
\hline \multirow{2}{*}{$\begin{array}{l}\text { Venous } \\
\text { invasion }\end{array}$} & Absent & 26 & 8 & \multirow{2}{*}{0.022} \\
\hline & Present & 116 & 93 & \\
\hline \multirow{2}{*}{$\begin{array}{l}\text { Lymph node } \\
\text { metastasis }\end{array}$} & Absent & 89 & 58 & \multirow{2}{*}{0.450} \\
\hline & Present & 54 & 43 & \\
\hline \multirow{2}{*}{ CEA (ng/ml) } & $<5$ & 106 & 64 & \multirow{2}{*}{0.049} \\
\hline & $\geq 5$ & 34 & 36 & \\
\hline
\end{tabular}

\section{${ }^{\mathrm{a}} \mathrm{X}^{2}$ test.}
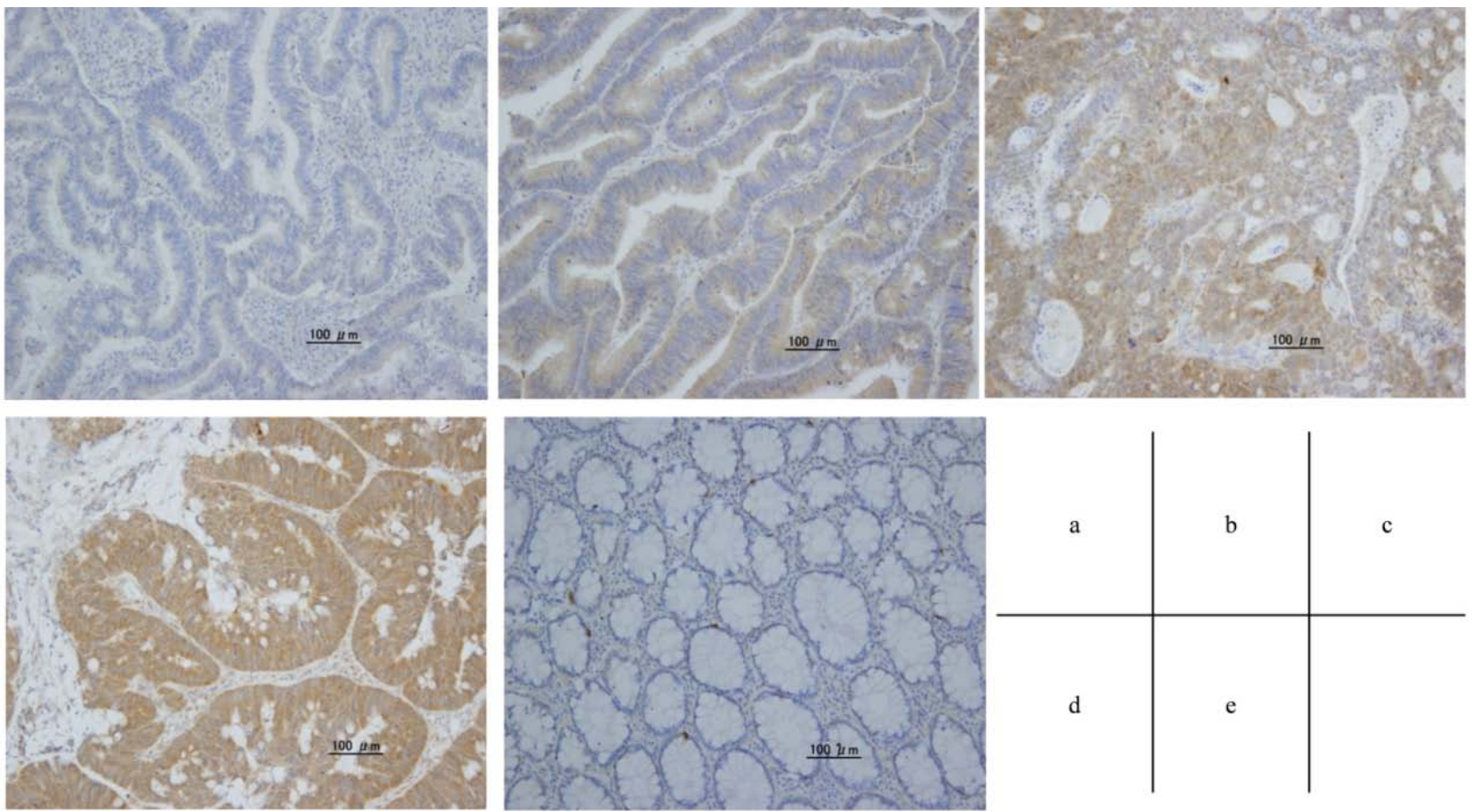

Figure 2. Representative of colorectal cancers and normal colorectal epithelium immunostaining for PDGFC: (a) 0 no staining; (b) 1+ weak staining; (c) 2+ moderate staining; (d) 3+ strong staining; (e) normal epithelium staining 1 (magnification $200 \times)$. 


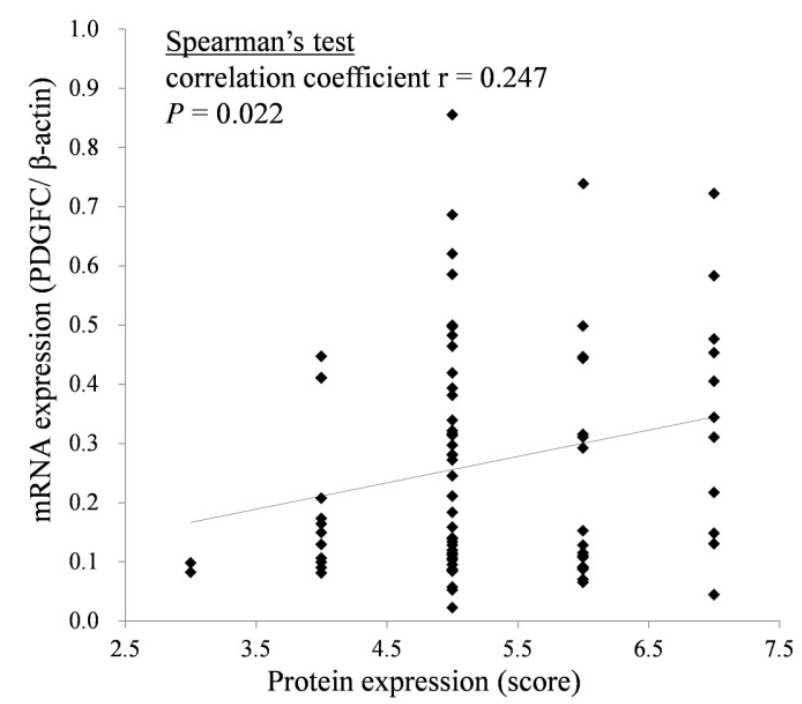

Figure 3. PDGFC mRNA expression was correlated with protein expression in the 85 patients who underwent RTPCR analysis and immunohistochemistry (correlation coefficient $r=0.247, P=0.022$ ).

0.022), and elevated serum CEA levels $(P=0.049)$ than the low expression group. In addition, the high expression group showed tended to have a higher number of male patients $(P=0.022)$. There were no significant differences in the factors of TNM staging (depth and lymph node metastasis) between the low expression and high expression groups among these patients. The relapse-free survival (RFS) and overall survival (OS) rates were significantly lower $(P<0.0001$ and $P<0.0001$, respectively) in patients with high PDGFC protein expression than in those with low PDGFC protein expression (Figure 4). Univariate analysis showed that the following factors were significantly associated with worse RFS: rectal cancer, moderately- or poorly-differentiated and other type of cancer, T4 tumor, lymphatic invasion, venous invasion, lymph node metastasis, an elevated CEA level, and high PDGFC expression (Table 2). Multivariate analysis using the Cox proportional hazards model indicated that lymph node metastasis and high PDGFC expression were associated with worse RFS (relative risk [RR] $=2.184, P$ $=0.012$ and $\mathrm{RR}=3.395, P<0.001$, respectively). Regarding OS, univariate analysis identified the following factors as significantly associated with worse OS: male, rectal cancer, moderately- or poorly-differentiated and other type of cancer, T4 tumor, lymphatic invasion, lymph node metastasis, an elevated CEA level, and high PDGFC expression (Table 3). Multivariate analysis indicated that gender $(\mathrm{RR}=2.900 ; P=0.05)$, location $(\mathrm{RR}$ 2.136; $P=0.041$ ), and PDGFC protein overexpression (RR $=3.374 ; P=0.006)$ were independent risk factors for the prognosis of patients with CRC.

\section{Discussion}

In this study, we investigated the correlation between PDGFC expression and clinicopathologic features in patients with CRC at both the mRNA and protein levels. The expression of PDGFC in cancer tissues was significantly higher in patients in the metastatic group than in those in the non-metastatic group, suggesting that PDGFC might contribute to metastasis in CRC. To determine whether PDGFC expression could predict the prognosis of patients with CRC after curative surgery, we performed immunohistochemical studies using samples from patients with stage I, II, or III disease. We found several significant correlations between PDGFC protein

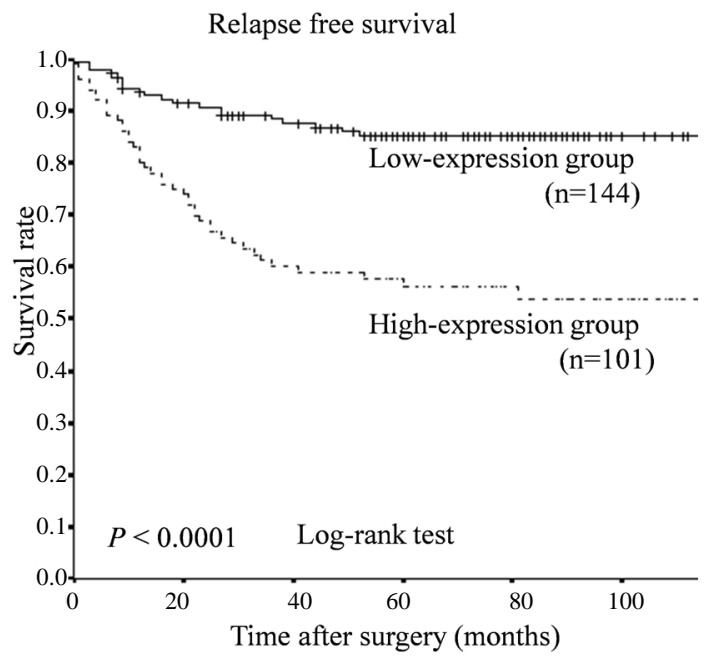

(a)

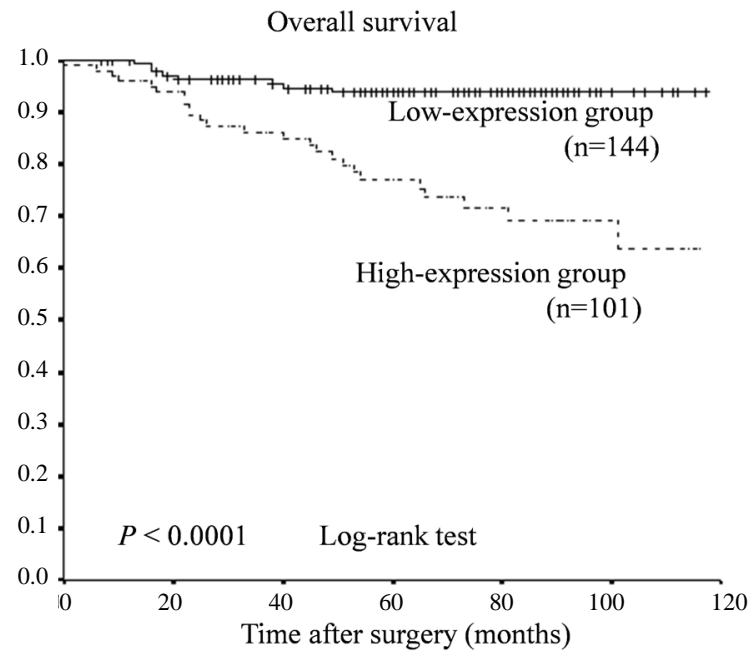

(b)

Figure 4. Kaplan-Meier curves for RFS (a) and OS (b) of 245 stage I to III CRC patients by PDGFC expression. The RFS and OS rates were significantly lower $(P<0.0001$ and $P<0.0001$, respectively) in patients with high PDGFC protein expression than in those with low PDGFC protein expression. 
Table 2. Univariate \& multivariate analysis of clinicopathological features affecting RFS in stage I-III CRCs (Cox proportional hazards model).

\begin{tabular}{|c|c|c|c|c|c|}
\hline \multirow{2}{*}{ Variables } & & \multirow{2}{*}{ No. patients } & \multirow{2}{*}{$\begin{array}{c}\text { Univariate analysis } \\
P\end{array}$} & \multicolumn{2}{|l|}{ Multivariate analysis } \\
\hline & & & & Relative risk (95\% confidence interval) & $P$ \\
\hline \multirow[t]{2}{*}{ Age } & $\leq 65$ & 122 & \multirow[b]{2}{*}{0.829} & & \\
\hline & & & & & \\
\hline \multirow{3}{*}{ Gender } & & & \multirow{3}{*}{0.070} & & \\
\hline & Male & 161 & & & \\
\hline & Female & 84 & & & \\
\hline \multirow[t]{3}{*}{ Location } & Colon & 163 & \multirow{3}{*}{0.028} & & \multirow{3}{*}{0.054} \\
\hline & Rectum & & & & \\
\hline & Rectum & 82 & & & \\
\hline \multirow[t]{2}{*}{ Histology } & Well & 103 & \multirow[b]{2}{*}{0.018} & & \multirow[b]{2}{*}{0.376} \\
\hline & Moderate, poor and others & 142 & & & \\
\hline \multirow[t]{2}{*}{ Depth } & $\mathrm{T} 1 / \mathrm{T} 2 / \mathrm{T} 3$ & 169 & \multirow[b]{2}{*}{$<0.001$} & & \multirow[b]{2}{*}{0.325} \\
\hline & $\mathrm{T} 4$ & 76 & & & \\
\hline \multirow[t]{3}{*}{ Lymphatic invasion } & Absent & 71 & \multirow{3}{*}{0.003} & & \multirow{3}{*}{0.438} \\
\hline & & & & & \\
\hline & Present & 173 & & & \\
\hline \multirow[t]{2}{*}{ Venous invasion } & Absent & 34 & \multirow[b]{2}{*}{0.029} & & \multirow[b]{2}{*}{0.759} \\
\hline & Present & 210 & & & \\
\hline \multirow[t]{2}{*}{ Lymph node metastasis } & Absent & 148 & \multirow[b]{2}{*}{$<0.001$} & 2.184 & \multirow[b]{2}{*}{0.012} \\
\hline & Present & 97 & & $(1.190-4.008)$ & \\
\hline \multirow[t]{3}{*}{ CEA (ng/ml) } & $<5$ & 170 & \multirow{3}{*}{$<0.001$} & & \multirow{3}{*}{0.152} \\
\hline & & & & & \\
\hline & $\geq 5$ & 71 & & & \\
\hline \multirow[t]{3}{*}{ PDGFC } & Low expression & 144 & \multirow{3}{*}{$<0.001$} & 3.395 & \multirow{3}{*}{$<0.001$} \\
\hline & Wirb & & & & \\
\hline & High expression & 101 & & $(1.895-6.081)$ & \\
\hline
\end{tabular}

expression and clinicopathologic factors. Moreover, multivariate analysis indicated that PDGFC protein overexpression was an independent and significant prognostic factor for CRC recurrence after curative surgery.

PDGFC is a mitogenic factor for cells of mesenchymal origin and appears to be involved in all three phases (inflammation, proliferation, and remodeling/maturation) of wound healing [11,17-22]. Several studies identified PDGFC as a potent antigenic factor, similar to VEGF and the classical PDGFs [11,23-25]. Abnormalities in the PDGF/PDGFR system such as constitutive activation of PDGFR kinases, activating mutations of the PDGFR kinases, and autocrine signaling due to overexpression of PDGFs and the PDGFRs contribute to a number of human diseases, especially malignancies including osteosarcomas, lung carcinomas, gliomas, malignant astrocytomas, and medulloblastomas [26,27]. Oncogenic transformation mediated by the autocrine PDGF loop occurs through activation of the ras/MAPK pathway, which in- creases cellular proliferation, and activation of the PI3K/ Akt pathway, which promotes cell survival [28]. The discovery that PDGFB is a v-sis homolog made PDGFB one of the earliest discovered oncogenes, connecting PDGF/ PDGFR to cellular transformation [29]. The finding that PDGFC acts similarly as PDGF-AB, the most mitogenic of all PDGFs [30], as it activates both PDGFR-AA and PDGFR-AB, indicates a role for PDGFC as an oncogene $[11,31]$. PDGFC induces tumor formation in nude mice, activates anchorage-dependent growth, and is a potent transforming growth factor in NIH/3T3 cells [32]. In vivo tumorigenesis may partially be explained by PDGFC-mediated VEGF expression, promoting indirect stimulation of tumor angiogenesis. Moreover, it is known that PDGFC behaves in a paracrine manner to recruit cancer-associated fibroblasts (CAFs) and promotes angiogenesis and tumor growth. Anderberg et al. revealed the functional significance of paracrine PDGFC signaling in the recruitment of CAFs into experimental mouse me- 
Table 3. Univariate \& multivariate analysis of clinicopathological features affecting OS in stage I-III CRCs (Cox proportional hazards model).

\begin{tabular}{|c|c|c|c|c|c|}
\hline \multirow{2}{*}{ Variables } & & \multirow{2}{*}{ No. patients } & \multirow{2}{*}{$\begin{array}{c}\text { Univariate analysis } \\
P\end{array}$} & \multicolumn{2}{|l|}{ Multivariate analysis } \\
\hline & & & & Relative risk (95\% confidence interval) & $P$ \\
\hline \multirow[t]{2}{*}{ Age } & $\leq 65$ & 122 & \multirow[b]{2}{*}{0.129} & & \\
\hline & $>65$ & 123 & & & \\
\hline \multirow[t]{2}{*}{ Gender } & Male & 161 & \multirow{2}{*}{0.013} & 2.900 & \multirow{2}{*}{0.050} \\
\hline & Female & 84 & & $(1.000-8.411)$ & \\
\hline \multirow[t]{2}{*}{ Location } & Colon & 163 & \multirow{2}{*}{0.037} & 2.136 & \multirow{2}{*}{0.041} \\
\hline & Rectum & 82 & & $(1.030-4.430)$ & \\
\hline \multirow[t]{2}{*}{ Histology } & Well & 103 & \multirow{2}{*}{0.009} & & \multirow{2}{*}{0.345} \\
\hline & Moderate, poor and others & 142 & & & \\
\hline \multirow[t]{2}{*}{ Depth } & T1/T2/T3 & 169 & \multirow{2}{*}{$<0.001$} & & \multirow{2}{*}{0.064} \\
\hline & $\mathrm{T} 4$ & 76 & & & \\
\hline \multirow[t]{2}{*}{ Lymphatic invasion } & Absent & 71 & \multirow{2}{*}{0.029} & & \multirow{2}{*}{0.703} \\
\hline & Present & 173 & & & \\
\hline \multirow[t]{2}{*}{ Venous invasion } & Absent & 34 & \multirow{2}{*}{0.079} & & \\
\hline & Present & 210 & & & \\
\hline \multirow[t]{2}{*}{ Lymph node metastasis } & Absent & 148 & \multirow{2}{*}{0.004} & & \multirow{2}{*}{0.279} \\
\hline & Present & 97 & & & \\
\hline \multirow{2}{*}{ CEA (ng/ml) } & $<5$ & 170 & \multirow{2}{*}{0.003} & & \multirow{2}{*}{0.257} \\
\hline & $\geq 5$ & 71 & & & \\
\hline \multirow[t]{2}{*}{ PDGFC } & Low expression & 144 & \multirow{2}{*}{$<0.001$} & 3.374 & \multirow[b]{2}{*}{0.006} \\
\hline & High expression & 101 & & $(1.412-8.064)$ & \\
\hline
\end{tabular}

lanoma, thereby augmenting both tumor growth and angiogenesis, and a paracrine signaling network involving PDGFC that regulates the recruitment of CAFs into tumors and their phenotype and is readily available for therapeutic intervention [15]. Concerning its significance in the treatment of cancer, some studies report the inhibition of tumor growth via the silencing of this gene. Li et al. demonstrated that PDGFC overexpression in established mouse tumor cell lines accelerates tumor growth via both autocrine and paracrine modes of action. Expression of antisense PDGFC mRNA partially inhibits tumor cell growth and tumor development in cells with endogenous PDGFC expression [33]. Several tyrosine kinase pathways are activated by overexpressed PDGFC in cancer cells via autocrine pathways, thereby promoting tumor growth and anti-apoptosis. It is possible that tumors with PDGFC-mediated PDGF-receptor activation are sensitive to tyrosine kinase inhibitors [34]. Thus, although many studies suggest that PDGFC plays an im- portant role in tumor growth, angiogenesis, and tumor microenvironment both in vivo and in vitro, its precise role in cancer and its impact on actual clinical outcomes remain unknown. In the present study, we observed that several clinical features were affected by the expression of PDGFC. This is the first study to demonstrate the relationship between PDGFC expression and prognosis in patients with CRC.

Despite curative surgery for localized disease, approximately $40 \%$ of patients with CRC will eventually relapse [35]. Recently, some adjuvant chemotherapies for patients with CRC were indicated to be associated with improved cure rates after surgery [36]. Despite the efficacy of these chemotherapies, they are costly and associated with severe adverse effects. Therefore, there exists a need to identify patients who would benefit from adjuvant chemotherapy prior to treatment; molecular markers may provide important insight concerning this challenge $[37,38]$, as these markers can be considered when select- 
ing the appropriate chemotherapy. Our study suggests that high PDGFC protein expression is predictive of recurrence after curative surgery for CRC. In the last decade, the development of novel therapies that target critical biological pathways has greatly expanded treatment options for patients with CRC and resulted in substantial improvements in survival [39]. PDGFC might be a useful biomarker to decide whether to use strong adjuvant chemotherapy in patients with CRC after curative surgery. In this study, a subset analysis of patients with stage III CRC revealed that patients with high PDGFC protein expression had a poor clinical outcome irrespective of the use of adjuvant chemotherapy after surgery (data not shown). Intensive adjuvant chemotherapy may be applicable for patients with CRC and high PDGFC expression even if they lack other conventional risk factors for recurrence. Multivariate analysis indicated that lymph node metastasis and PDGFC protein expression are independent prognostic factors for recurrence. Therefore, application of PDGFC expression together with a prognostic indicator such as TNM classification might improve the prediction of prognosis in patients with CRC. Furthermore, although there is no evidence of synergy between cytotoxic chemotherapy and molecular targeted drugs for adjuvant therapy after curative surgery, multiple targeted RTK inhibitors may have efficacy against PDGFC-overexpressing CRC because PDGFC may play a role in the activation of RTK pathways according to some reports. Moreover, because PDGFC is overexpressed mainly in cancer cells whereas it is not expressed or only weakly expressed in normal cells, it may be a novel target for cancer treatment without adverse effects on normal cells.

\section{Conclusion}

In conclusion, overexpression of PDGFC in CRCs was correlated with recurrence and poor prognosis. PDGFC may be a predictive biomarker of CRC recurrence and a target for the treatment of this disease.

\section{Acknowledgements}

We thank Y. Takagi, S. Kishiro and J. Inoue for excellent technical assistance.

\section{REFERENCES}

[1] R. Siegel, D. Naishadham and A. Jemal, "Cancer Statistics, 2012,” CA: A Cancer Journal for Clinicians, Vol. 62, No. 1, 2012, pp. 10-29. http://dx.doi.org/10.3322/caac.20138

[2] H. Kobayashi, H. Mochizuki, T. K. Sugihara, Morita, K. Kotake, T. Teramoto, et al., "Characteristics of Recurrence and Surveillance Tools after Curative Resection for Colorectal Cancer: A Multicenter Study,” Surgery, Vol. 141, No. 1, 2007, pp. 67-75. http://dx.doi.org/10.1016/j.surg.2006.07.020

[3] J. Weitz, M. Koch, J. Debus, T. Hohler, P. R. Galle and M. W. Buchler, "Colorectal Cancer," Lancet, Vol. 365, No. 9454, 2005, pp. 153-165. http://dx.doi.org/10.1016/S0140-6736(05)17706-X

[4] A. B. Benson III, D. Schrag, M. R. Somerfield, A. M. Cohen, A. T. Figueredo, P. J. Flynn, et al., "American Society of Clinical Oncology Recommendations on Adjuvant Chemotherapy for Stage II Colon Cancer,” Journal of Clinical Oncology, Vol. 22, No. 16, 2004, pp. 34083419. http://dx.doi.org/10.1200/JCO.2004.05.063

[5] J. Merla and S. Goel, "Novel Drugs Targeting the Epidermal Growth Factor Receptor and Its Downstream Pathways in the Treatment of Colorectal Cancer: A Systematic Review," Chemotherapy Research and Practice, Vol. 1, 2012, pp. 225-235.

[6] M. Inanç, O. Er, H. Karaca, V. Berk, M. Ozkan, R. Saraymen, et al., "Prognostic Value of Tumor Growth Factor Levels during Chemotherapy in Patients with Metastatic Colorectal Cancer,” Medical Oncology, Vol. 29, No. 5, 2012, pp. 3119-3124. http://dx.doi.org/10.1007/s12032-012-0250-8

[7] M. Skobe and N. E. Fusenig, "Tumorigenic Conversion of Immortal Human Keratinocytes through Stromal Cell Activation," Proceedings of the National Academy of Sciences of the United States of America, Vol. 95, No. 3, 1998, pp. 1050-1055.

http://www.pnas.org/content/95/3/1050.full http://dx.doi.org/10.1073/pnas.95.3.1050

[8] K. Forsberg, I. Valyi-Nagy, C. H. Heldin, M. Herlyn and B. Westermark, "Platelet-Derived Growth Factor (PDGF) in Oncogenesis: Development of a Vascular Connective Tissue Stroma in Xenotransplanted Human Melanoma Producing PDGF-BB,” Proceedings of the National Academy of Sciences of the United States of America, Vol. 90, 1993, pp. 393-397.

http://www.pnas.org/content/90/2/393.long http://dx.doi.org/10.1073/pnas.90.2.393

[9] Z. M. Shao, M. Nguyen and S. H. Barsky, "Human Breast Carcinoma Desmoplasia Is PDGF Initiated,” Oncogene, Vol. 19, No. 38, 2000, pp. 4337-4345. http://dx.doi.org/10.1038/sj.onc.1203785

[10] M. L. Tejada, L. L. Yu, J. Y. Dong, K. Jung, G. Meng, F. V. Peale, et al., “Tumor-Driven Paracrine Platelet-Derived Growth Factor Receptor Alpha Signaling Is a Key Determinant of Stromal Cell Recruitment in a Model of Human Lung Carcinoma," Clinical Cancer Research, Vol. 12, 2006, pp. 2676-2688. http://dx.doi.org/10.1158/1078-0432.CCR-05-1770

[11] D. G. Gilbertson, M. E. Duff, J. W. West, J. D. Kelly, P. O. Sheppard, P. D. Hofstrand, et al., "Platelet-Derived Growth Factor C (PDGF-C), a Novel Growth Factor That Binds to PDGF Alpha and Beta Receptor,” Journal of Biological Chemistry, Vol. 276, 2001, pp. 27406-27414. http://dx.doi.org/10.1074/jbc.M101056200

[12] X. Li, A. Pontén, K. Aase, L. Karlsson, A. Abramsson, M. Uutela, et al., "PDGF-C Is a New Protease-Activated Ligand for the PDGF Alpha-Receptor,” Nature Cell Biology, Vol. 2, 2000, pp. 302-309. 
http://dx.doi.org/10.1038/35010579

[13] J. S. Campbell, S. D. Hughes, D. G. Gilbertson, T. E. Palmer, M. S. Holdren, A. C. Haran, et al., "Platelet-Derived Growth Factor C Induces Liver Fibrosis, Steatosis, and Hepatocellular Carcinoma," Proceedings of the $\mathrm{Na}$ tional Academy of Sciences of the United States of America, Vol. 102, No. 9, 2005, pp. 3389-3394. http://dx.doi.org/10.1073/pnas.0409722102

[14] E. Borkham-Kamphorst, E. Kovalenko, C. R. C. van Roeyen, N. Gassler, M. Bomble, T. Ostendorf, et al., "Platelet-Derived Growth Factor Isoform Expression in Carbon Tetrachloride-Induced Chronic Liver Injury,” Laboratory Investigation, Vol. 88, No. 10, 2008, pp. 10901100.

[15] C. Anderberg, H. Li, L. Fredriksson, J. Andrae, C. Betsholtz, X. R. Li, et al., "Paracrine Signaling by PlateletDerived Growth Factor-CC Promotes Tumor Growth by Recruitment of Cancer-Associated Fibroblasts," Cancer Research, Vol. 69, 2009, pp. 369-378. http://dx.doi.org/10.1158/0008-5472.CAN-08-2724

[16] T. Maass, F. R. Thieringer, A. Mann, T. Longerich, P. Schirmacher, D. Strand, et al., "Liver Specific Overexpression of Plateletderived Growth Factor-B Accelerates liver Cancer Development in Chemically Induced Liver Carcinogenesis," International Journal of Cancer, Vol. 128, No. 6, 2010, pp. 1259-1268. http://dx.doi.org/10.1002/ijc.25469

[17] X. Li, A. Pontén, K. Aase, L. Karlsson, A. Abramsson, M. Uutela, et al., "PDGF-C Is a New Protease-Activated Ligand for the PDGF Alpha-Receptor," Nature Cell Biology, Vol. 2, 2000, pp. 302-309. http://dx.doi.org/10.1038/35010579

[18] H. Ding, X. Wu, H. Boström, I. Kim, N. Wong, B. Tsoi, et al., "A Specific Requirement for PDGF-C in Palate Formation and PDGFR-Alpha Signaling," Nature Genetics, Vol. 36, 2004, pp. 1111-1116. http://dx.doi.org/10.1038/ng1415

[19] A. T. Grazul-Bilska, M. L. Johnson, J. J. Bilski, D. A. Redmer, L. P. Reynolds, and A. Abdullah and K. M. Abdullah, "Wound Healing: The Role of Growth Factors," Drugs Today (Barc), Vol. 39, No. 10, 2003, pp. 787-800. http://dx.doi.org/10.1358/dot.2003.39.10.799472

[20] L. Fang, Y. Yan, L. G. Komuves, S. Yonkovich, C. M. Sullivan, B. Stringer, et al., "PDGF C Is a Selective Alpha Platelet-Derived Growth Factor Receptor Agonist That Is Highly Expressed in Platelet Alpha Granules and Vascular Smooth Muscle,” Arteriosclerosis, Thrombosis, and Vascular Biology, Vol. 24, 2004, pp. 787-792. http://dx.doi.org/10.1161/01.ATV.0000120785.82268.8b

[21] X. Li, M. Tjwa, L. Moons, P. Fons, A. Noel, A. Ny, et al., "Revascularization of Ischemic Tissues by PDGF-CC via Effects on Endothelial Cells and Their Progenitors," The Journal of Clinical Investigation, Vol. 115, No. 1, 2005, pp. 118-127.

[22] M. Jinnin, H. Ihn, Y. Mimura, Y. Asano, K. Yamane and K. Tamaki, "Regulation of Fibrogenic/Fibrolytic Genes by Platelet-Derived Growth Factor C, a Novel Growth Factor, in Human Dermal Fibroblasts,” Journal of Cellular Physiology, Vol. 202, No. 2, 2005, pp. 510-517. http://dx.doi.org/10.1002/jcp.20154

[23] R. Cao, E. Brakenhielm, X. Li, K. Pietras, J. Widenfalk, A. Ostman, et al., "Angiogenesis Stimulated by PDGFCC, a Novel Member in the PDGF Family, Involves Activation of PDGFR-Alphaalpha and -Alphabeta Receptors," The Journal of Federation of American Societies for Experimental Biology, Vol. 16, No. 12, 2002, pp. 1575-1583. http://dx.doi.org/10.1096/fj.02-0319com

[24] F. Eitner, T. Ostendorf, C. Van Roeyen, M. Kitahara, X. Li, K. Aase, et al., "Expression of a Novel PDGF Isoform, PDGF-C, in Normal and Diseased Rat Kidney,” Journal of the American Society of Nephrology, Vol. 13, No. 4, 2002, pp. 910-917.

http://www.ncbi.nlm.nih.gov/pubmed/11912250

[25] S. Taneda, K. L. Hudkins, S. Topouzis, D. G. Gilbertson, V. Ophascharoensuk, L. Truong, et al., "Obstructive Uropathy in Mice and Humans: Potential Role for PDGF-D in the Progression of Tubulointerstitial Injury," Journal of the American Society of Nephrology, Vol. 14, No. 10, 2003, pp. 2544-2555.

http://www.ncbi.nlm.nih.gov/pubmed/14514732 http://dx.doi.org/10.1097/01.ASN.0000089828.73014.C8

[26] N. A. Lokker, C. M. Sullivan, S. J. Hollenbach, M. A. Israel and N. A. Giese, "Platelet-Derived Growth Factor (PDGF) Autocrine Signaling Regulates Survival and Mitogenic Pathways in Glioblastoma Cells: Evidence That the Novel PDGF-C and PDGF-D Ligands May Play a Role in the Development of Brain Tumors," Cancer Research, Vol. 62, No. 13, 2002, pp. 3729-3735. http://www.ncbi.nlm.nih.gov/pubmed/12097282

[27] J. Andrae, C. Molander, A. Smits, K. Funa and M. Nister, "Platelet-Derived Growth Factor-B and -C and Active Alpha-Receptors in Medulloblastoma Cells,” Biochemical and Biophysical Research Communications, Vol. 296, No. 3, 2002, pp. 604-611. http://dx.doi.org/10.1016/S0006-291X(02)00917-8

[28] T. Rosenmuller, K. Rydh and E. Nanberg, "Role of Phosphoinositide 3OH-Kinase in Autocrine Transformation by PDGF-BB,” Journal of Cellular Physiology, Vol. 188, 2001, pp. 369-382. http://dx.doi.org/10.1002/jcp.1126

[29] R. F. Doolittle, M. W. Hunkapiller, L. E. Hood, S. G. Devare, K. C. Robbins, S. A. Aaronson, et al., "Simian Sarcoma Virus Onc Gene, v-Sis, Is Derived from the Gene (or Genes) Encoding a Platelet-Derived Growth Factor,” Science, Vol. 221, No. 4607, 1983, pp. 275-277. http://dx.doi.org/10.1126/science.6304883

[30] S. Ekman, E. R. Thuresson, C. H. Heldin and L. Ronnstrand, "Increased Mitogenicity of an Alphabeta Heterodimeric PDGF Receptor Complex Correlates with Lack of RasGAP Binding,” Oncogene, Vol. 18, No. 15, 1999, pp. 2481-2488. http://dx.doi.org/10.1038/sj.onc.1202606

[31] J. P. Zwerner and W. A. May, "Dominant Negative PDGF-C Inhibits Growth of Ewing Family Tumor Cell Lines,” Oncogene, Vol. 21, No. 24, 2002, pp. 3847-3854. http://dx.doi.org/10.1038/sj.onc.1205486

[32] H. Li, L. Fredriksson, X. Li and U. Eriksson, "PDGF-D Is a Potent Transforming and Angiogenic Growth Factor," Oncogene, Vol. 22, 2003, pp. 1501-1510. http://dx.doi.org/10.1038/sj.onc.1206223 
[33] X. Li and U. Eriksson, "Novel PDGF Family Members: PDGF-C and PDGF-D," Cytokine \& Growth Factor Reviews, Vol. 14, No. 2, 2003, pp. 91-98. http://dx.doi.org/10.1016/S1359-6101(02)00090-4

[34] U. McDermott, R. Y. Ames, A. J. Iafrate, S. Maheswaran, H. Stubbs, P. Greninger, et al., "Ligand-Dependent Platelet-Derived Growth Factor Receptor (PDGFR)-Alpha Activation Sensitizes Rare Lung Cancer and Sarcoma Cells to PDGFR Kinase Inhibitors,” Cancer Research, Vol. 69, 2009, pp. 3937-3946. http://dx.doi.org/10.1158/0008-5472.CAN-08-4327

[35] E. C. Johnstone and D. J. Kerr, "What Is the Role and Impact of Molecular Markers on Treatment Decisions in the Adjuvant Setting of Colorectal Cancer?” Annals of Oncology, Vol. 19, Suppl. 7, 2008, pp. vii184-vii186. http://dx.doi.org/10.1093/annonc/mdn455

[36] T. Andre, C. Boni, L. Mounedji-Boudiaf, M. Navarro, J. Tabernero, T. Hickish, et al., "Oxaliplatin, Fluorouracil, and Leucovorin as Adjuvant Treatment for Colon Cancer,"
The New England Journal of Medicine, Vol. 350, 2004, pp. 2343-2351. http://dx.doi.org/10.1056/NEJMoa032709

[37] S. Aballéa, J. V. Chancellor, M. Raikou, M. F. Drummond, M. C. Weinstein, S. Jourdan, et al., "Cost-Effectiveness Analysis of Oxaliplatin Compared with 5-Fluorouracil/Leucovorin in Adjuvant Treatment of Stage III Colon Cancer in the US,” Cancer, Vol. 109, No. 6, 2007, pp. 1082-1089. http://dx.doi.org/10.1002/cncr.22512

[38] B. M. Wolpin and R. J. Mayer, "Systemic Treatment of Colorectal Cancer,” Gastroenterology, Vol. 134, No. 5, 2008, pp. 1296-1310.

http://dx.doi.org/10.1053/j.gastro.2008.02.098

[39] H. Hurwitz, L. Fehrenbacher, W. Novotny, T. Cartwright, J. Hainsworth, W. Heim, et al., "Bevacizumab plus Irinotecan, Fluorouracil, and Leucovorin for Metastatic Colorectal Cancer," The New England Journal of Medicine, Vol. 350, 2004, pp. 2335-2342. http://dx.doi.org/10.1056/NEJMoa032691 